\title{
Moderators of implicit-explicit exercise cognition concordance
}

Berry, Tanya; Rodgers, Wendy; Markland, David; Hall, Craig

\section{Journal of Sport and Exercise Psychology}

DOI:

10.1123/jsep.2016-0174

Published: 31/12/2016

Cyswllt i'r cyhoeddiad / Link to publication

Dyfyniad o'r fersiwn a gyhoeddwyd / Citation for published version (APA):

Berry, T., Rodgers, W., Markland, D., \& Hall, C. (2016). Moderators of implicit-explicit exercise cognition concordance. Journal of Sport and Exercise Psychology, 38(6), 579-589.

https://doi.org/10.1123/jsep.2016-0174

\footnotetext{
Hawliau Cyffredinol / General rights

Copyright and moral rights for the publications made accessible in the public portal are retained by the authors and/or other copyright owners and it is a condition of accessing publications that users recognise and abide by the legal requirements associated with these rights.

- Users may download and print one copy of any publication from the public portal for the purpose of private study or research.

- You may not further distribute the material or use it for any profit-making activity or commercial gain

- You may freely distribute the URL identifying the publication in the public portal ?
}

Take down policy

If you believe that this document breaches copyright please contact us providing details, and we will remove access to the work immediately and investigate your claim. 
Moderators of implicit-explicit exercise cognition concordance

Manuscript accepted 26.10.16

Journal of Sport and Exercise Psychology

\author{
Tanya R. Berry ${ }^{\mathrm{a}}$ \\ Wendy M. Rodgers, $\mathrm{PhD}^{\mathrm{a}}$ \\ David Markland ${ }^{\mathrm{b}}$ \\ Craig Hall ${ }^{\mathrm{c}}$ \\ ${ }^{\text {a}}$ Faculty of Physical Education and Recreation \\ University of Alberta \\ Edmonton, AB, Canada T6G 2H9 \\ ${ }^{\mathrm{b}}$ David Markland, PhD \\ School of Sport, Health \& Exercise Sciences \\ Bangor University \\ Bangor, UK \\ 'School of Kinesiology \\ Western University \\ Room 4161, Thames Hall \\ London, Ontario, Canada, N6A 5B9
}




\begin{abstract}
Investigating implicit-explicit concordance can aid in understanding underlying mechanisms and possible intervention effects. This research examined the concordance between implicit associations of exercise with health or appearance and related explicit motives. Variables considered as possible moderators were behavioral regulations, explicit attitudes, and social desirability. Participants $(\mathrm{N}=454)$ completed measures of implicit associations of exercise with health and appearance, and questionnaire measures of health and appearance motives, attitudes, social desirability, and behavioral regulations. Attitudes significantly moderated the relationship between implicit associations of exercise with health and health motives. Identified regulations significantly moderated implicit-explicit concordance with respect to associations with appearance. These results suggest that implicit and explicit exercise-related cognitions are not necessarily independent and their relationship to each other may be moderated by attitudes or some forms of behavioral regulation. Future research that takes a dual-processing approach to exercise behavior should consider potential theoretical moderators of concordance.
\end{abstract}

Keywords: automatic associations, explicit motivation; exercise; attitudes; self-regulation; dualprocessing 
Implicit-explicit exercise concordance 3

\section{Moderators of implicit-explicit exercise cognition concordance}

Researchers have begun to understand the importance of examining implicit cognitions in relation to health behavior (cf. Sheeran, Golwitzer, \& Bargh, 2013). Dual processing models such as the Associative Propositional Evaluation Model (APE; Gawronski \& Bodenhausen, 2011) consider both 'implicit' and 'explicit' cognitions such as motives. Implicit cognitions are considered to be fast, automatic responses whereas explicit cognitions are relatively slow, effortful by cognitive processing standards, and deliberate (it takes work to consciously think about something; Deutsch \& Strack, 2010). In the APE, implicit cognitions are conceptualized as associations that are automatically activated by an object or topic and explicit cognitions such as motives represent endorsement of how much one considers those associations to be true (Gawronski \& Bodenhausen, 2011). For example, at an implicit level, exercise-related stimuli could activate automatic associations with health and at an explicit level, if a person is motived to exercise for health, they will explicitly endorse this motive.

The relationship between implicit and explicit cognitions has long been a source of debate (Hofmann \& Wilson, 2010). Initially believed to be independent, it is now generally thought that they are (or can be) concordant, and that the concordance might be moderated by cognitive or motivational factors such that the relationship between implicit and explicit constructs is affected. There is a need to study under what circumstances there might be implicitexplicit concordance so that underlying mechanisms are understood (Hofmann, Gschwendner, \& Schmitt, 2005). Investigating concordance can also provide insight into intervention effects because discrepant implicit-explicit cognitions are weaker and may be more readily influenced (Karpen, Jia, \& Rydell, 2012). These researchers found that when pro-exercise behaviors were made salient, participants with greater discrepancy had higher exercise-related self-beliefs and 
attitudes; when anti-exercise behaviors were made salient those with greater discrepancy had more negative self-beliefs and attitudes. These authors further showed that explicit attitudes toward alcohol were more related to behavior when implicit-explicit attitudes were concordant, rather than discrepant, and behavior may be affected when both implicit and explicit constructs are high or both are low.

Various factors that might influence concordance have been proposed (Hyde, Doerksen, Ribeiro, \& Conroy, 2010), but there have been limited empirical tests of possible moderators within the exercise domain. In other areas, Brown and Cordon (2009) review how skills such as mindfulness may increase emotional self-awareness and subsequent implicit-explicit concordance. Hyde et al. (2010) explored the influence of introspective access (i.e., the extent to which a person has meta-awareness of implicit effects on their behavior; Hofmann \& Wilson, 2010) on concordance of implicit and explicit attitudes toward exercise, but found no effect. They proposed a number of other potential moderators such as the value of exercise, social desirability, and intrinsic motivation. The present research sought to test these possibilities with carefully constructed measures of implicit associations of exercise with health and appearance and corresponding explicit motivation measures; health and appearance were chosen because they are commonly cited reasons for exercising (Ingledew \& Markland, 2008).

The APE model posits that implicit-explicit concordance will depend on the extent to which automatically activated evaluations are used in making explicit judgements (Garwonski \& Bodenhausen, 2006; 2011). Implicit-explicit concordance has been found to be higher when people are asked to focus on feelings regarding gay and straight people rather than on the reasons for preferring gay or straight people (Tucker Smith, \& Nosek, 2011). For affect, these authors used statements about how gay or straight people make them feel compared to cognition 
statements such as rating beliefs about characteristics of gay and straight people. In the current research, participants completed an explicit attitudes measure of the personal value of exercise rather than general beliefs about exercise. In accordance with Tucker Smith and Nosek, it is proposed that stronger explicit exercise-related attitudes should lead to greater implicit-explicit concordance because, when exercise is highly valued, positive aspects of health or appearance will be automatically associated with exercise and considered 'true' at an explicit level. This is consistent with expectancy-value theory wherein expectations of behavior (e.g., exercise will lead to looking good) and the value of the goal to be active jointly influence motivation (Lowe \& Norman, 2013). As such, the implicit measure was also created to reflect desirable or undesirable expectations of what exercise can achieve.

Another possible moderator to consider is social desirability (Hyde et al., 2010). Social desirability has long been proposed as a possible moderator of implicit-explicit concordance largely due to the idea that it is easier to deliberately modify answers on an explicit measure than it is on an implicit measure (Gawronski, 2009). As such, concordance should be higher when social desirability is low because, presumably, explicit responses are not adjusted. However, the evidence in support of this idea is mixed; Gawronski stated "the correspondence between implicit measures and self-reports is far more complex than just a matter of social desirability and self-presentation” (p. 144). Nonetheless, following the suggestion of Hyde and colleagues (2010), social desirability was tested as a possible moderator in the current research. It may be that people overstate health as a motivator while downplaying appearance as a motivator for exercise behavior, both due to a need for impression management, since 'health' is (arguably) regarded as a more socially desirable pursuit than appearance. 
Intrinsic motivation has also been proposed as a possible moderator of the implicitexplicit relationship (Hyde et al, 2010). According to self-determination theory (SDT; Ryan \& Deci, 2000), intrinsic motivation is the most self-determined form of behavioral regulation such that those who are intrinsically motivated engage in a behavior because of the inherent interest and satisfaction derived from taking part. In contrast, there are a number of behavioral regulations that reflect extrinsic motivations. One such form is external regulation where a person may exercise only to satisfy the wishes of someone else such as a family member. A more self-determined form of regulation is introjected regulation, which reflects a partially internalised motivation that comes from pressures one places on oneself and to avoid negative emotions such as guilt over not being active or to enhance one’s self-esteem. External and introjected regulations are accompanied by feelings of pressure to act and are therefore considered non-selfdetermined forms of motivation. Identified regulation is a more internalised and self-determined form of motivation where one engages in a behavior through the desire to achieve outcomes important or personally valued (e.g., health). Integrated regulation is motivation that is fully internalised so that it is congruent with one's self-identity and broader values and is a fully selfdetermined form of motivation. Finally, an individual can be amotivated, which reflects no intention to engage in a behavior (Ryan \& Deci, 2000).

All forms of behavioral regulation will be tested as moderators in this research because although intrinsic motivation may strengthen concordance much in the same way that valuing exercise might (as suggested by Hyde et al., 2010), it is possible that less self-determined regulations may also be related to concordance. For example, exercise may be automatically associated with health, but if one feels pressure to exercise for this reason, explicit motives for health may be low. Therefore, it is posited that greater implicit-explicit concordance will be 
associated with more internalised regulations (identified, integrated and intrinsic), because these are more aligned with one's personal goals, values and identity. Conversely, if exercise is not internalised (i.e., a person is amotivated, or they have high levels of external or introjected regulation) then it would be expected that there would be implicit-explicit discrepancy because a person may not have strong associations of exercise in memory, or there may be conflicts within a person regarding exercise because they don't want to do it, and these conflicts weaken concordance.

The purpose of this research was to examine attitudes, social desirability, and behavioral regulations as possible moderators of the concordance of implicit associations of exercise with health or appearance and related explicit motives. Implicit measures of associations between exercise and health and appearance were constructed based on an extant explicit measure (the Exercise Motivations Inventory 2; Markland \& Ingledew, 1997). The following hypotheses were put forward: H1) Stronger explicit attitudes will be related to greater concordance between implicit associations of exercise with health and appearance and explicit motives for health and appearance; H2) Higher social desirability will be related to lower implicit-explicit concordance; H3) Greater internalization of exercise (i.e., identified, integrated, and intrinsic regulations) will be related to greater implicit-explicit concordance whereas less internalised regulations (i.e., external and introjected) or amotivation will not be related to concordance.

\section{Method}

\section{Participants}

Participants aged 35 to 65 years were recruited for a study that, as advertised, asked: "what do you think about exercise?” At the end of the study, participants were given 
Implicit-explicit exercise concordance 8

information about a free year-long exercise program and asked if they would like to join. The data reported here are from all the participants, prior to being offered the exercise program.

\section{Materials and Procedure}

Demographic information. Participants self-reported sex, age, and race (open-ended), yearly family income (from less than $\$ 5000$ to greater than $\$ 100,000$ in nine increments), education, marital status, and weight and height (used to calculate body mass index [BMI]).

Physical activity. The Godin Leisure-Time Exercise Questionnaire (GLTEQ; Godin \& Shephard, 1997) measured weekly frequency of strenuous (characterized as heart beats rapidly, sweating) and moderate (characterized as not exhausting, light perspiration) leisure-time physical activity in bouts 15 minutes or longer. As recommended by Godin (2011), a weekly moderate to vigorous physical activity score (MVPA) was calculated by multiplying the reported number of bouts of moderate activity by 5 ; and strenuous activity by 9 ; and summing the products.

Implicit associations. Participants completed two Go/No Go Association Tasks (GNATs; Nosek \& Banaji, 2001). The GNAT is a measure of automatic associations and was used to measure automatic associations of exercise with 1) health and 2) appearance. In the tasks, participants were presented with words that consisted of a target category comprising exercise words: activity, sports, run, workout, physical activity, gym, and exertion, or a contrast target category of generic words matched for frequency of use in the English language: bookshelf, retailer, carpet, flannel, ink, mug, and rental. The evaluative category for this research was desirable/undesirable to represent possible outcomes of exercise. The two GNATs differed on the focus of the evaluative category. In one, the evaluative dimension included pairs of words representing physical and mental health, intrinsic motivation, and fitness outcomes of exercise: healthy-sick, fit-unfit, strong-weak, energetic-tired, relaxed-stressed, fun-boring, good mood-bad 
mood. In the other they represented appearance, societal norms for body shape and size, and extrinsic motivations: attractive-unattractive, toned-flabby, thinner-fatter, winner-loser, look good-look bad, popular-unpopular, and weight loss-weight gain.

Participants were instructed to categorize each word, as it appeared, to its assigned attribute (e.g., exercise/desirable, exercise/undesirable) by hitting the space bar (go) as fast as they could, or to ignore words that did not belong to the assigned category (no go). A fixation cross was shown for 500 milliseconds (msec) preceding each trial and the response deadline for categorizing targets was 850 msec. Response time (RT) was used as the outcome measure. A longer response deadline was chosen and response time (RT) used as the outcome measure because the appropriate response deadline to measure sensitivity with a large heterogeneous sample (such as that recruited for the current research) is not certain due to increased response time with age, and with increased intrasubject variability particularly in women (Der \& Deary, 2006). Feedback in the form of a red " $\mathrm{X}$ " for an error or a blue "O" for a correct response was provided after each trial. Four blocks of trials were completed ("go" categories of exercise/desirable, generic/desirable, exercise/undesirable, generic/undesirable). Each block comprised practice trials (subsets of experimental stimuli with only one category to respond to) and 48 experimental trials with equal numbers of target and distracter trials. There was a short break between each block during which participants were told the target words for the upcoming block. The block order was counterbalanced so that some participants categorized exercise and desirable words first, others exercise and undesirable first, and so on. The GNAT variant (health or appearance) order was also counterbalanced across participants.

Responses were screened for errors and response times faster than 250 msec. Reliability, calculated using odd/even experimental trials, of the health/fitness GNAT was adequate with 
reliability for exercise and desirable $\alpha=.87$ and intraclass correlation $=.77, p<.001$; and for exercise and undesirable $\alpha=.67$ and intraclass correlation $=.51, p<.001$. Reliability of the appearance GNAT was also adequate with reliability for exercise and desirable $\alpha=.83$ and intraclass correlation $=.72, p<.001$; and for exercise and undesirable $\alpha=.80$ and intraclass correlation $=.66, p<.001$. Implicit outcome measures were calculated by subtracting the mean responses to exercise and desirable trials from exercise and undesirable trials. Thus a positive score indicates a positive association, a score near zero indicates no association, and a negative score indicates associating exercise with undesirable things (e.g., unfit).

Explicit Motives. Two items each from the positive health and appearance subscales of the Motivations for Exercise Inventory 2 (EMI-2; Markland \& Ingledew, 1997) were used. The EMI-2 assesses participatory motives for exercise which are distinct from behavioral regulations for exercise in that the former reflect the content of individuals’ exercise goals (i.e., specific reasons for exercising) whereas the latter reflect the extent to which the locus of causality for a behavior is more external or more internal (Ingledew, Markland, \& Strömmer, 2014). All statements were answered on a scale ranging from 0 (not at all true for me) to 5 (very true for me) starting with the stem "Personally, I exercise (or might exercise)...” and mean scores of items from each subscale were calculated. Health motives were assessed with the statements “to have a healthy body" and "to feel more healthy" ( $r=.57, \alpha=.73)$, and appearance motives with the statements "to improve my appearance" and "to have a good body" $(\mathrm{r}=.63, \alpha=.77)$.

Attitudes. This construct was measured with the mean responses to five items, rated on a 1-9 semantic differential scale, as recommended by Ajzen (2002), that started with: "For me to be active 3 days per week for at least 30 minutes at a moderate intensity level will be...” 
worthless/valuable, useless/useful, harmful/beneficial, aggravating/calming, and exhausting/invigorating; $\alpha=.89$. Higher scores indicate a more positive attitude.

Social Desirability. The Marlowe-Crowne Social Desirability Scale (Crowne \& Marlowe, 1960) includes 33 items rated as true (1) or false (0). A sum score of the items rated 'true' measures the extent to which a person behaves in a socially desirable way, $\alpha=.81$.

Behavioral Regulations. These were measured with the Behavioral Regulations for Exercise Questionnaire-3 (BREQ-3; Markland \& Tobin, 2004; Wilson, Rodgers, Loitz, \& Scime, 2006). This questionnaire is a modification of the BREQ-2 with the addition of an integrated regulation subscale (Wilson et al., 2006). The BREQ-3 includes scales rated from 0 (not true for me) to 4 (very true for me) that measure amotivation (e.g., I don’t see why I should have to exercise; 4 items, $\alpha=.82$ ), external regulation (e.g., I take part in exercise because my friends/family/spouse say I should; 4 items, $\alpha=.82$ ), introjected regulation (e.g., I feel guilty when I don't exercise; 3 items, $\alpha=.76$ ), identified regulation (e.g., it’s important to me to exercise regularly; 4 items, $\alpha=.79$ ), integrated regulation (e.g., I exercise because it is consistent with my life goals; 4 items, $\alpha=.90$ ) and intrinsic regulation (e.g., I exercise because it’s fun; 4 items, $\alpha=.89$ ). A mean score was created for each subscale.

\section{Procedure}

All procedures were approved by a university health research ethics review panel and informed consent was obtained from all participants prior to starting the study. Participants individually completed the two GNAT tasks followed by the questionnaires in a quiet room with only a research assistant present.

\section{Data analysis}


Implicit-explicit exercise concordance 12

Prior to calculating explicit attitude and explicit motivation scores, a confirmatory factor analysis using LISREL 8.8 was conducted to determine the discriminant validity of attitudes, and explicit health and appearance motivation. Anderson-Rubin covariance preserving factor scores (Beauducel, 2007) were created during this process to use as constructs in the moderation test because they reproduce the latent variable covariance matrix, thus accounting for measurement error. The moderation analyses followed a similar plan to Hyde et al. (2010) but used multivariate linear regression models in which multiple outcomes are regressed simultaneously on the predictors, with interaction terms between implicit associations and the moderators. All models included gender, age, MVPA, and BMI, implicit associations and one of the possible moderators, and interaction terms between the implicit associations and each moderator variable. Age, MVPA, BMI, and the implicit association scores were mean-centred prior to inclusion in the models. Finally, correlations were calculated to determine if explicit-implicit discrepancy was related to MVPA. There were some missing data at baseline, most frequently in BMI ( $\mathrm{n}=$ 34; 7.4\%) and social desirability $(n=36 ; 7.8 \%)$. These data were missing at random, Little’s $\operatorname{MCAR} X^{2}(230)=234.15, p=.41$, and so multiple imputations $(\mathrm{m}=5)$ were used to replace missing data.

\section{Results}

A total of 460 people participated in the study, mean age of $48.34(S D=8.66)$ years; $69.8 \%$ [ $n=321]$ female. Over half the sample were married or living in a common-law relationship ( $n=274,59.6 \%)$. They were for the most part highly educated: $76(16.5 \%)$ had high school or less, 143 (31.1\%) had some college education, 127 (27.6\%) had a bachelor’s degree, and $86(18.7 \%)$ had a graduate or professional degree, with 16 (3.5\%) listing other or none of the above, and 12 with missing data (2.6\%). The median household income was between $\$ 50,000$ 
Implicit-explicit exercise concordance 13

and \$74,999 Canadian dollars (52 participants did not report this information). The majority selfidentified as Caucasian or White $(n=310 ; 67.4 \%)$. Self-reported physical activity scores, categorized according to criteria outlined by Godin (2011), indicated 281 (61.1\%) were insufficiently active, 82 (17.8\%) were moderately active and 97 (21.1\%) were sufficiently active for health benefits. The mean BMI was $29.75(S D=7.70)$. There were 5 participants with extreme scores on implicit health or implicit appearance ( $>3 S D$ from the mean) and they were excluded, leaving a final sample of 455 .

Confirmatory Factor Analysis (CFA). Discriminatory validity of the attitude, EMI-2 and BREQ subscales were assessed using CFA in which items were predictors of their relative constructs. Results showed acceptable fit for the model, Chi-square $(428)=1132.05, p<.001$; RMSEA $=.062$ (CI: .058 - .067), $p<.001 ; \mathrm{NNFI}=.96$; CFI $=.968$. The ranges of the standardized factor loadings for the variables were: attitudes $=.72-.83$, explicit health $=.78-.80$, explicit appearance $=.76-.87$, amotivation $=.72-.80$, external regulations $.67-.84$, introjected regulations .64 - .84, identified regulations .55 - .82, integrated regulations .78 - .85, and intrinsic regulations .81 - .90. Latent variable correlations ranged from +/-.02 to .82. None of the $95 \%$ confidence intervals for the correlations encompassed unity. Thus, discriminant validity was achieved.

Regression models. Table 1 shows the means, standard deviations, and correlations between all variables included in the models, a number of which were significant due to the sample size. The implicit scores reported are the differences between responding to exercise and desirable and exercise and undesirable; the questionnaire scores reported are the raw scores prior to transformation. Separate models assessed attitudes, social desirability, and each of the behavioral regulations because a multivariate regression with all predictors in one model showed 
the presence of suppressor variables (e.g., integrated and intrinsic regulations had negative beta weights when predicting explicit health and appearance motives) and multicollinearity (several tolerance values <.15 and variance inflation factors $>7$ ). Table 2 summarizes the regression models. For parsimony of space, age, gender, MVPA, and BMI are not reported, and only the standardized beta weights for the final models are shown. In the health models, gender and age were significant predictors (women had higher scores than men and greater age was related to stronger health motives). In the appearance models, gender was a significant predictor (women had higher scores than men). Neither MVPA nor BMI were significant in any models.

Attitude was a significant moderator in the health model. Follow up with simple slopes analysis showed the slope for low attitudes levels was significant, $t(456)=-2.63, p<.01$, but slopes for medium and high levels were not, both $p>.24$. This relationship is shown in the lefthand panel of Figure 1. As shown in Table 2, other significant predictors of health motives were attitudes, social desirability, amotivation, introjected, identified, integrated, and intrinsic regulations and all were positively related except for amotivation.

Significant moderators in the appearance models included attitudes and identified regulations. Follow up with simple slopes with identified regulations as the moderator showed a significant slope for high identified regulations, $t(456)=-2.28, p<.05$, but the other slopes were not significant, both $p>.25$. This relationship is shown in the right-hand panel of Figure 1 . Follow-up simple slopes analyses with the implicit health - attitudes interaction was not significant, $p>.10$. As shown in Table 2, other significant predictors of appearance motives were attitudes, amotivation, introjected, identified, integrated, and intrinsic regulations and all were positively related except for amotivation. 
Implicit-explicit exercise concordance 15

Relationship of Implicit-explicit discrepancy to MVPA. In accordance with prior work (e.g., Shoda, McConnell \& Rydell, 2014), implicit-explicit discrepancies were calculated by subtracting the standardized explicit health or appearance scores (i.e., the health and appearance Anderson-Rubin covariance preserving factor scores) from the corresponding implicit health or appearance scores (i.e., the mean-centred scores). The correlations between the health discrepancy scores and MVPA was not significant, $r=-.01$, nor was the correlation between appearance discrepancy scores and MVPA, $r=.004$.

\section{Discussion}

This research examined exercise-related attitudes, social desirability, and behavioral regulations as possible moderators of the concordance between implicit associations of exercise with health or appearance and extrinsic health or appearance motives. By doing so, further understanding of the relationship between implicit and explicit exercise-related constructs was gained. It was hypothesized that greater implicit-explicit concordance would be demonstrated among participants with (H1) stronger explicit exercise-related attitudes, (H2) lower social desirability, and (H3) with more self-determined exercise regulations. It is important to keep in mind the large sample of adults, $30 \%$ of whom men, with an average age of 48 years and an average BMI of about 30. There are few previous studies that engage such a group. The inclusion criterion of being between the ages of 35 and 65 resulted in one of very few samples that does not include a younger demographic that, arguably, holds different types of motives for exercise (cf. Strömmer, Ingledew, \& Markland, 2015). Thus, new insight into the relationship of implicit and explicit cognitions can be offered.

The attitudes-related hypothesis was supported, but only for the health model. As shown in the left-hand panel of Figure 1, among participants with lower exercise-related attitudes, 
stronger automatically activated associations of exercise with health were related to lower explicit health motives. Even though people with weaker attitudes toward exercise still may have strong automatic associations between exercise and health, they may not particularly value it, or its association with health as an outcome, and so are not likely to report wanting to exercise to be healthy. It is also possible that they think exercise is generally related to health, but not for themselves specifically. Similar relationships were not found for automatically activated appearance-related associations and explicit motivations. Previous research has shown that implicit and explicit beliefs of exercise and health messages were correlated but implicit and explicit beliefs of appearance messages were not related (Berry, Jones, McLeod, \& Spence, 2011). The current research supports the idea that relevant beliefs should be considered within the implicit-explicit relationship.

It is also possible that, in this particular sample, health is 'top-of-mind' in a ubiquitous way. Indeed, an important caveat to the current research is the near ceiling scores for explicit health motives and exercise-related attitudes and the strong positive relationship of exercise with health at an implicit level. In fact, both types of automatic associations were strongly related to exercise, which likely reflects strong memory stores of these concepts in relation to exercise (Nosek et al, 2011). This is not surprising as both health and appearance are frequently and strongly associated with exercise by myriad sources such as public health (exercise and health), commercial fitness organizations (exercise and appearance with a tacit nod to health), and the media (both, frequently) (Maibach, 2007; Cusumano \& Thompson, 1997). The near ceiling scores mean there is little variability and this may have influenced the results. However, the evidence here is quite strong that the extent to which a thoroughly socially entrenched idea like 'exercise for health’ must be questioned in terms of its implications for behavior as it appears 
that most people are strongly aware of 'exercise for health', and hold implicit and explicit associations accordingly, the concordance of which are affected by related attitudes.

It was also hypothesized that identified, integrated, and intrinsic regulations (more selfdetermined), but not external, introjected regulations, or amotivation (less self-determined), would be related to greater implicit-explicit concordance. This was not supported in the health models but identified regulations moderated implicit-explicit appearance concordance. As shown in the right hand panel of Figure 1, lower scores on the identified regulation scale were related to greater implicit-explicit concordance at the low end. That is, among participants with the lowest identified regulations, negative or weak associations of exercise were related to lower appearance motives. This raises the question of when such concordance positively or negatively predicts behavior. In the current research, participants with low identified regulations but strong implicit associations of exercise with appearance still had relatively low appearance motives; lower, in fact, than those with medium or high identified regulations. Although the slope is not significant, participants with high identified regulations and the strongest appearance associations, compared to those with lower appearance associations, reported lower appearance motives. It may be that participants in the current study who most strongly felt it was important to exercise regularly were not motivated for appearance reasons, and thus rejected the automatically activated associations of exercise with appearance, or these associations, although present, were simply not related to their explicit motives.

Social desirability was also tested as a moderator because it has been suggested by many researchers that greater social desirability will lead to less implicit-explicit concordance because of adjustments to explicit responses (Gawronski, 2009). However, in accordance with Gawronski's position that it is overly simplistic to consider that implicit-explicit concordance is 
based on self-presentational concerns, this hypothesis was not supported. There was a small significant correlation between social desirability and health motives, but this was not related to implicit-explicit concordance. It may be that the very high scores on the health subscale of the EMI-2 found in the present research are somewhat due to social desirability. It is also possible that there was little cognitive elaboration about health in relation to exercise; that is, participants didn't really think about the relationship between exercise and health, and just agreed, with little deliberation, on the explicit measure (Gawronski \& Bodenhausen, 2011). This is consistent both with the wide-spread association of exercise with health and the social desirability of wanting to be healthy. It may be that strongly held desires of people considering exercise are not explicitly acknowledged, but wanting to be healthy is an easy and acceptable reason to express.

The size and nature of the sample in this study are a considerable strength, and support the credibility of the study findings. This sample allows for confidence in the inferences that can be made about the relationships between implicit associations and explicit exercise motives among adults willing to participate in a study about thoughts about exercise. However, a possible limitation of the present study is that participation took place in university-based research facilities with adjacent fitness centers. Associations can be automatically activated by the context in which the attitude object is encountered (Gawronski \& Bodenhausen, 2011). Thus, if testing had taken place in a neutral context with no link to exercise, disease, or health, or in a commercial fitness facility that may have greater appearance connotations, results may have differed. This is an intriguing consideration for future research and indeed for administering exercise-related interventions as the setting may influence decisions to participate as well as responses to measures. It is equally important to note that all participants were tested in this context, so there is no contextual variability that might have influenced responses. Finally, 
participants were recruited to indicate "what they think about exercise”, possibly setting up an experimental demand effect. To assess this problem, it would be necessary to invite participation in a study not specifically about exercise and to include exercise questions.

It is also important to recognize the danger of endogeneity in regression models where the predictors are correlated with the error term because of omitted variable bias (Antonakis, Bendahan, Jacquart, \& Lalive, 2010, 2014). Although we controlled for gender, age, BMI, and MVPA which are potential sources of endogeneity, future research should test other possibilities. For example, internalization of social or media pressures could influence exercise-related attitudes, motives, and behavioral regulations. Further, the moderation effects are quite small. Thus, these effects require replication and should be interpreted with caution. In addition, there are other potential moderators that could be examined in future research to fully understand how implicit and explicit exercise-related cognitions are related. For example, exercise schema is a potential moderator because implicit exercise-related attitudes are stronger in exercise schematics (Berry, Spence, \& Clark, 2011). Although Banting, Dimmock, and Lay (2011) found both implicit and explicit exercise self-schemas were related to exercise behavior, they also found they were not isomorphic. Nonetheless, this discrepancy is of interest because schemas are related to information processing and greater implicit-explicit discrepancy is related to more information processing in an attempt to reduce the cognitive dissonance that arises due to the discrepancy (Rydell, McConnell, \& Mackie, 2008).

In general, the implicit-explicit correlations were quite low in the current research but it seems unlikely that lack of concordance is due to independent systems as posited by some (cf., Hofmann et al., 2005). Although care was taken in the current research in designing the measures, future research should investigate implicit-explicit concordance with other exercise-related 
implicit and explicit measures. As noted, it is likely the ceiling scores on the explicit health measure accounted for some of this issue. There was also no relationship between implicitexplicit concordance (or lack thereof) and MVPA. Concordance has been related to alcohol consumption (Karpen et al., 2012), and it may be that implicit-explicit concordance is more related to impulsive decisions such as taking the stairs, rather than MVPA over one week. Future research should also consider how implicit-explicit concordance is related to exercise behavior, both objectively measured and longitudinally. Implicit-explicit discrepancy is related to information processing (Rydell et al., 2008), and it may also be that participants with weak exercise-related attitudes and discrepant implicit-explicit cognitions may be more open to processing exercise-related information. In conclusion, this study indicates that implicit and explicit exercise-related constructs are not necessarily independent and their concordance may be moderated by attitudes or some forms of behavioral regulation. Future research that takes a dualprocessing approach to exercise behavior should consider such moderators of concordance.

Acknowledgements. The authors would like to thank the anonymous reviewers for their comments on earlier versions of this manuscript, particularly for the statistical insights from one reviewer which improved the quality of the manuscript. We would also like to acknowledge [funding bodies, blinded for peer review]. 
Implicit-explicit exercise concordance 21

\section{References}

Antonakis, J., Bendahan, S., Jacquart, P., \& Lalive, R. (2014). Causality and endogeneity: Problems and solutions. In D.V. Day (Ed.), The Oxford Handbook of Leadership and Organizations (pp. 93-117). New York, NY: Oxford University Press.

Antonakis, J., Bendahan, S., Jacquart, P., \& Lalive, R. (2010). On making causal claims: A review and recommendations. The Leadership Quarterly, 21, 1086-1120. doi: 10.1016/j.leaqua.2010.10.010.

Ajzen, I. (2002). Constructing a TpB Questionnaire: Conceptual and methodological considerations. Retrieved from www.people.umass.edu/aizen/pdf/tpb.measurement.pdf

Banting, L. K., Dimmock, J. A., \& Lay, B. S. (2009). Implicit and explicit components of exerciser self-schema in the prediction of exercise behavior. Psychology of Sport and Exercise, 10, 80-86. doi:10.1016/j.psychsport.2008.07.007

Beauducel, A. (2007). In spite of indeterminacy many common factor score estimates yield an identical reproduced covariance matrix. Psychometrika, 72, 437-441. doi: 10.1007/s11336-005-1467-5.

Berry, T. R., Jones, K. E., McLeod, N. C., \& Spence, J. C. (2011). The relationship between implicit and explicit believability of exercise-related messages and intentions. Health Psychology, 30, 746-752. doi: 10.1037/a0025082.

Berry, T. R., Spence, J. C., \& Clark, M. I. (2011). Exercise is in! Implicit exercise and sedentarylifestyle bias held by in-groups. Journal of Applied Social Psychology, 41, 2985-2998. doi:10.1111/j.1559-1816.2011.00857.x 
Implicit-explicit exercise concordance 22

Brown, K. W., \& Cordon, S. (2009). Toward a phenomenology of mindfulness: subjective experience and emotional correlates. In F. Didonna (Ed.), Clinical Handbook of Mindfulness (pp. 59-81). New York: Springer.

Crowne, D. P., \& Marlowe, D. (1960). A new scale of social desirability independent of psychopathology. Journal of Consulting Psychology, 24, 349-354.

Cusumano, D. L., \& Thompson, J. K. (1997). Body image and body shape ideals in magazines: Exposure, awareness, and internalization. Sex Roles, 37, 701-721.

Der, G., \& Deary, I. J. (2006). Age and Sex Differences in Reaction Time in Adulthood: Results From the United Kingdom Health and Lifestyle Survey. Psychology and Aging, 21, 62-73.

Deutsch, R., \& Strack, F. (2010). Building blocks of social behavior: Reflective and impulsive processes. In B. Gawronski \& B. K. Payne (Eds.), Handbook of Implicit Social Cognition (pp. 62 - 79). New York: Guilford.

Gawronski, B. (2009). Ten frequently asked questions about implicit measures and their frequently supposed, but not entirely correct answers. Canadian Psychology, 50, 141-150. doi: $10.1037 / \mathrm{a} 001384$

Gawronski, B. \& Bodenhausen, G. V. (2011). The associative-propositional evaluation model: Theory, evidence, and open questions. Advances in Experimental Social Psychology, 44, $59-127$.

Godin, G. \& Shephard, R. J. (1997). Godin Leisure-Time Exercise Questionnaire. Medicine and Science in Sports and Exercise, 29, S36-S38.

Godin, G. (2011). The Godin-Shephard leisure-time physical activity questionnaire. Health and Fitness Journal of Canada, 4, 18-22. 
Hofmann, W., Gschwendner, T., \& Schmitt, M. (2005). On implicit-explicit consistency: the moderating role of individual differences in awareness and adjustment. European Journal of Personality, 19, 25-49. doi: 10.1002/per.537

Hofmann, W. \& Wilson, T. D. (2010). Consciousness, introspection, and the adaptive unconscious. In B. Gawronski \& B. K. Payne (Eds.), Handbook of Implicit Social Cognition (pp. 197 - 215). New York: Guilford.

Hyde, A. L., Doerksen, S. E., Ribeiro, N. F., \& Conroy, D. E. (2010). The independence of implicit and explicit attitudes toward physical activity: Introspective access and attitudinal concordance. Psychology of Sport and Exercise, 11, 387-393.

Ingledew, D. K., \& Markland, D. (2008). The role of motives in exercise participation. Psychology \& Health, 23, 807-828.

Ingledew, D.K., Markland, D., \& Strömmer, S.S. (2014). Elucidating the roles of motives and gains in exercise participation. Sport, Exercise \& Performance Psychology, 3, 116-131.

Karpen, S. C., Jia, L., \& Rydell, R. J. (2012). Discrepancies between implicit and explicit attitude measures as an indicator of attitude strength. European Journal of Social Psychology, 42, 24-29.

Lowe, R. \& Norman, P. (2013). Attitudinal approaches to health behavior: integrating expectancy-value and automaticity accounts. Social and Personality Psychology Compass, 7, 572-584. doi: 10.1111/spc3.12046

Maibach, E. (2007). The influence of the media environment on physical activity: Looking for the big picture. American Journal of Health Promotion, 21 (Suppl 4), 353-362. doi: http://dx.doi.org/10.4278/0890-1171-21.4s.353 
Implicit-explicit exercise concordance 24

Markland, D., \& Ingledew, D.K. (1997). The measurement of exercise motives: Factorial validity and invariance across gender of a revised Exercise Motivations Inventory. British Journal of Health Psychology, 2, 361-376. doi: 10.1111/j.2044-8287.1997.tb00549.x

Markland, D. \& Tobin, V. (2004). A modification of the Behavioral Regulation in Exercise Questionnaire to include an assessment of amotivation. Journal of Sport and Exercise Psychology, 26, 191-196

Nosek, B. A., \& Banaji, M. R. (2001). The go/no-go association task. Social Cognition, 19, 625666.

Nosek, B. A., Hawkins, C. B., \& Frazier, R. S. (2011). Implicit social cognition: from measures to mechanism. Trends in Cognitive Sciences, 15, 152-159. doi:10.1016/j.tics.2011.01.005

Ryan, R. M., \& Deci, E. L. (2000). Self-determination theory and the facilitation of intrinsic motivation, social development, and well-being. American Psychologist, 55, 68-78.

Rydell, R. J., McConnell, A. R., \& Mackie, D. M. (2008). Consequences of discrepant explicit and implicit attitudes: Cognitive dissonance and increased information processing. Journal of Experimental Social Psychology, 44, 1526-1532.

Segar, M., Spruijt-Metz, D., \& Nolen-Hoeksema, S. (2006). Go figure? Body-shape motives are associated with decreased physical activity participation among midlife women. Sex Roles, 54, 175-187. doi: 10.1007/s11199-006-9336-5

Sheeran, P., Gollwitzer, P. M., \& Bargh, J. A. (2013). Nonconscious processes and health. Health Psychology, 32, 460-473. doi: 10.1037/a0029203

Shoda, T. M., McConnell, A. R., \& Rydell, R. J. (2014). Having explicit-implicit evaluation discrepancies triggers race-based motivated reasoning. Social Cognition, 32, 190-202. 
Strack, F., \& Deutsch, R. (2004). Reflective and impulsive determinants of social behavior. Personality and Social Psychology Review, 8, 220-227.

Strömmer, S.S., Ingledew, D.K., \& Markland, D. (2015). Development of the Exercise Motives and Gains Inventory. Measurement in Physical Education and Exercise Science, 19, 5368. doi:10.1080/1091367X.2015.1036162

Teixeira, P. J., Carraça, E. V., Markland, D. A., Silva, M. N., \& Ryan, R. M. (2012). Exercise, physical activity, and self-determination theory: A systematic review. Journal of Behavioral Nutrition and Physical Activity, 9, 78. doi:10.1186/1479-5868-9-78

Tucker Smith, C. \& Nosek, B. A. (2011). Affective Focus Increases the Concordance Between Implicit and Explicit Attitudes. Social Psychology, 42, 300-313. doi: 10.1027/18649335/a000072

Wilson, P.M., Rodgers, W.M., Loitz, C.C., \& Scime, G. (2006). “It’s who I am...really!” The importance of integrated regulation in exercise contexts. Journal of Biobehavioral Research, 11, 79-104. 
Table 1

Correlations and Means for all outcome and moderator variables

\begin{tabular}{|c|c|c|c|c|c|c|c|c|c|c|c|c|}
\hline Variable & $\mathrm{M}(\mathrm{SD})$ & 1 & 2 & 3 & 4 & 5 & 6 & 7 & 8 & 9 & 10 & 11 \\
\hline 1. Implicit health & $53.69(54.35)$ & - & & & & & & & & & & \\
\hline $\begin{array}{l}\text { 2. Implicit } \\
\text { appearance }\end{array}$ & $41.24(49.20)$ & $.22 * * *$ & - & & & & & & & & & \\
\hline $\begin{array}{l}\text { 3. Explicit health } \\
\text { motive }\end{array}$ & 4.57 (.69) & .09 & .01 & - & & & & & & & & \\
\hline $\begin{array}{l}\text { 4. Explicit } \\
\text { appearance } \\
\text { motive }\end{array}$ & $3.93(1.11)$ & .05 & -.01 & $.43 * * *$ & - & & & & & & & \\
\hline 5. Attitudes & $7.79(1.58)$ & $.10^{*}$ & .09 & $.41 * * *$ & $.14^{* *}$ & - & & & & & & \\
\hline $\begin{array}{l}\text { 6. Social } \\
\text { desirability }\end{array}$ & $18.76(5.54)$ & .02 & -.02 & $.13^{* *}$ & .05 & $.12^{* *}$ & - & & & & & \\
\hline 7. Amotivation & $0.43(0.71)$ & -.05 & -.06 & $-.34 * * *$ & $-.19 * * *$ & $-.29 * * *$ & -.07 & - & & & & \\
\hline $\begin{array}{l}\text { 8. External } \\
\text { regulation }\end{array}$ & $0.75(0.92)$ & -.02 & -.03 & -.03 & -.004 & -.07 & $-.11 *$ & $.25 * * *$ & - & & & \\
\hline $\begin{array}{l}\text { 9.Introjected } \\
\text { regulation }\end{array}$ & $1.50(1.14)$ & .06 & .04 & $.24 * * *$ & $.30 * * *$ & $.18^{* * *}$ & -.04 & $-.25 * * *$ & $.23 * * *$ & - & & \\
\hline $\begin{array}{l}\text { 10. Identified } \\
\text { regulation }\end{array}$ & $2.53(1.01)$ & .05 & $.10^{*}$ & $.37 * * *$ & $.25 * * *$ & $.35 * * *$ & .09 & $-.52 * * *$ & -.07 & $.39 * * *$ & - & \\
\hline 11. Integrated & $1.55(1.13)$ & .01 & -.01 & $.24 * * *$ & $.20 * * *$ & $.33 * * *$ & .07 & $-.32 * * *$ & $-.03 *$ & $.35 * * *$ & $.72 * * *$ & - \\
\hline
\end{tabular}


Implicit-explicit exercise concordance 27

regulation

12. Intrinsic $2.24(1.11) \quad .02$ $-.04$

$.25 * * *$

$.15^{* * *}$

$.29 * * *$

.08

$-.47 * * *$

$-.10$

$.30 * * *$ $72 * * *$

$.69 * * *$ regulation

$* p<.05 ; * * p<.01 ; * * * p<.001$ 
Table 2

Summaries of regression models

\begin{tabular}{|c|c|c|c|c|c|c|c|}
\hline Moderator & $\begin{array}{l}\text { Multivariate } \\
\text { F }\end{array}$ & Model & $\begin{array}{l}\beta \text { implicit } \\
\text { health }\end{array}$ & $\begin{array}{c}\beta \text { implicit } \\
\text { appearance }\end{array}$ & $\beta$ Moderator & $\begin{array}{l}\beta \text { Health- } \\
\text { moderator } \\
\text { interaction }\end{array}$ & $\begin{array}{c}\beta \text { Appearance } \\
\text { moderator } \\
\text { interaction }\end{array}$ \\
\hline Attitudes & $\mathrm{F}=9.30 * * *$ & $\begin{array}{l}\text { Appearance } \mathrm{R}^{2}=.08^{* *} \\
\text { adjusted } \mathrm{R}^{2}=.06\end{array}$ & -.07 & .02 & $.21 * * *$ & $.10^{*}$ & -.04 \\
\hline \multirow[t]{2}{*}{$\begin{array}{l}\text { Social } \\
\text { desirability }\end{array}$} & \multirow[t]{2}{*}{$\mathrm{F}=2.19 * *$} & $\begin{array}{l}\text { Health } \mathrm{R}^{2}=.07 \\
\text { adjusted } \mathrm{R}^{2}=.05\end{array}$ & -.04 & $.10^{*}$ & $.12 * *$ & -.03 & .03 \\
\hline & & $\begin{array}{l}\text { Appearance } \mathrm{R}^{2}=.04 \\
\text { adjusted } \mathrm{R}^{2}=.02\end{array}$ & -.05 & .05 & .08 & -.05 & .04 \\
\hline \multirow[t]{2}{*}{$\begin{array}{l}\text { External } \\
\text { regulations }\end{array}$} & \multirow[t]{2}{*}{$\mathrm{F}=2.15^{* *}$} & $\begin{array}{l}\text { Health } \mathrm{R}^{2}=.05^{*} \\
\text { adjusted } \mathrm{R}^{2}=.04\end{array}$ & -.03 & $.09 *$ & -.01 & .06 & .001 \\
\hline & & $\begin{array}{l}\text { Appearance } \mathrm{R}^{2}=.04^{*} \\
\text { adjusted } \mathrm{R}^{2}=.02\end{array}$ & -.06 & .05 & .004 & .002 & .03 \\
\hline $\begin{array}{l}\text { Introjected } \\
\text { regulations }\end{array}$ & $\mathrm{F}=6.44 * * *$ & $\begin{array}{l}\text { Health } \mathrm{R}^{2}=.16^{* * *} \\
\text { adjusted } \mathrm{R}^{2}=.14\end{array}$ & -.03 & .07 & $.33 * * *$ & .01 & -.05 \\
\hline
\end{tabular}


Implicit-explicit exercise concordance 29

\begin{tabular}{|c|c|c|c|c|c|c|c|}
\hline \multirow{3}{*}{$\begin{array}{l}\text { Identified } \\
\text { regulations }\end{array}$} & \multirow{3}{*}{$\mathrm{F}=11.43^{* * *}$} & $\begin{array}{l}\text { Appearance } \mathrm{R}^{2}=.17^{* * * *} \\
\text { adjusted } \mathrm{R}^{2}=.15\end{array}$ & -.05 & .03 & $.35 * * *$ & -.05 & -.04 \\
\hline & & $\begin{array}{l}\text { Health } \mathrm{R}^{2}=.34^{* * *} \\
\text { adjusted } \mathrm{R}^{2}=.33\end{array}$ & -.004 & .03 & $.55 * * *$ & .07 & -.07 \\
\hline & & $\begin{array}{l}\text { Appearance } \mathrm{R}^{2}=.16^{* * *} \\
\text { adjusted } \mathrm{R}^{2}=.14\end{array}$ & -.03 & .01 & $.33 * * *$ & .07 & $-.13^{* *}$ \\
\hline $\begin{array}{l}\text { Integrated } \\
\text { regulations }\end{array}$ & $\mathrm{F}=5.22 * * *$ & $\begin{array}{l}\text { Appearance } \mathrm{R}^{2}=.11^{* * * *} \\
\text { adjusted } \mathrm{R}^{2}=.09\end{array}$ & -.05 & .03 & $.27 * * *$ & .04 & -.05 \\
\hline $\begin{array}{l}\text { Intrinsic } \\
\text { motivation }\end{array}$ & $\mathrm{F}=4.40^{* * *}$ & $\begin{array}{l}\text { Health } \mathrm{R}^{2}=.13^{* * *} \\
\text { adjusted } \mathrm{R}^{2}=.12\end{array}$ & -.02 & .07 & $.28 * * *$ & .08 & -.06 \\
\hline
\end{tabular}

$* p<.05 ;{ }^{* *} p<.01 ; * * * p<.001$ 


\section{Figure 1}

Simple slopes graphs showing attitudes as a moderator of implicit-explicit health concordance and identified regulations as a moderator of implicit-explicit appearance concordance.
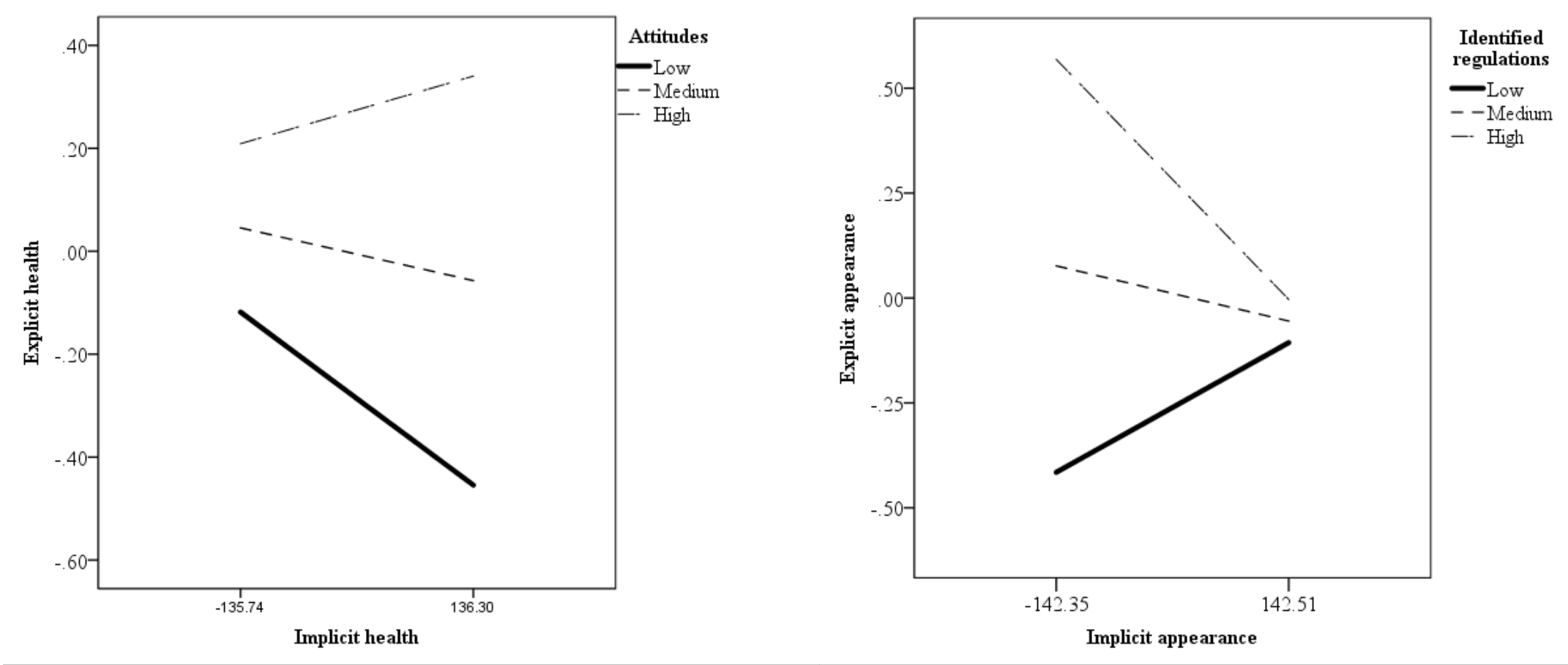